\title{
PROGRAMAS SOCLAIS, A EXCLUSÃO SOCIAL E A VEDAÇAO AO RETROCESSO: DIREITOS SOCIAIS NO BRASIL EM CRISE
}

\author{
SOCIAL PROGRAMS, SOCIAL EXCLUSION AND PROHIBITION \\ OF "RATCHET EFFECT": SOCIAL RIGHTS IN BRAZIL IN CRISIS \\ Alexandre Godoy Dotta ${ }^{1}$ \\ Camila Salgueiro da Purificação Marques ${ }^{2}$
}

\begin{abstract}
Recebido em: 15/05/2017 Aceito em: 28/12/2017

godoydotta@hotmail.com camila_purificacao@yahoo.com.br
\end{abstract}

Resumo: O trabalho trata dos programas sociais e do princípio da vedação ao retrocesso dos direitos sociais garantidos pela Constituição, com inspiração no atual cenário político e econômico brasileiro, verificando de que formas as medidas anunciadas pelo atual governo, pós processo de Impeachment, a exemplo das restrições nos programas sociais "Minha Casa, Minha Vida" e "Bolsa Família", podem constituir verdadeiro retrocesso em relação aos direitos sociais que já haviam sido em parte efetivados - o que fere a igualdade e acaba por gerar uma classe de pessoas "excluídas". Para tanto, verifica-se a questão da vedação ao retrocesso em relação aos direitos sociais, em razão dos princípios da proteção da confiança, da isonomia e da dignidade da pessoa humana, mormente no período de crise no Brasil, assim como se aborda a "inclusão do outro", sob a ótica de Habermas, identificando a ausência de diálogo para a decisão de restrição de tais direitos, e, ainda, que o sujeito, diante de tão intensa violação dos direitos sociais, não é abarcado por nenhuma posição democrática, perdendo a identidade e a noção de pertencimento social.

Palavras-chave: Democracia, Direitos sociais, Inclusão, Princípio da vedação ao retrocesso, Programas sociais.

\begin{abstract}
The paper focuses on the social programs and the prohibiton of ratchet effect which are guaranteed by the Brazilian Constitution. The paper was inspired by the current Brazilian political and economic environment and intends to verify how the measures announced by the current Brazilian government that took office after Dilma Roussef's Impeachment (v.g., restrictions on social programs like Brazilian housing program, school attendance-dependent social assistance program) may be a step backwards for social rights that had already been partly effected - which hurts equality and ultimately generates an "excluded" class of people. Therefore, the paper studies the prohibiton of the ratchet effect on relation to social rights, estabilishing its relations with the principles of trust protection, equality and human dignity, especially through the crisis period in Brazil, as well as addresses the "inclusion of the other" from the Habermas perspective, identifying the lack of dialogue that drives the Brazilian President decisions to restrict such rights. At last, the paper studies the people situation under so intense violation of their social rights, people which are not under protection by any democratic position, losing the identity and the notion of social belonging.
\end{abstract}

Keywords: Democracy, Social, Prohibition of ratchet effect, Social programs, Inclusion.

\section{INTRODUÇÃO}

O contexto de crise institucional e o cenário político brasileiro atuais inspiraram o presente trabalho a tratar da questão da vedação ao retrocesso na seara dos direitos sociais. Isso porque, com o afastamento da Presidente Dilma Rousseff (que foi eleita democraticamente, pela segunda vez, em outubro de 2014), por meio do processo de Impeachment, assumiu a Presidência o seu, até então

\footnotetext{
${ }^{1}$ Centro Universitário Autônomo do Brasil - UniBrasil - Curitiba - Paraná - Brasil

2 Pontifícia Universidade Católica do Paraná - PUCPR - Curitiba - Paraná - Brasil
} 
vice, Michel Temer, que vem anunciando medidas restritivas em relação aos programas sociais "Minha Casa, Minha Vida", "Bolsa Família", "Prouni" e outros, assim como tem agido na contramão dos progressos obtidos na efetivação dos direitos dos trabalhadores e dos aposentados.

Nesse contexto, diante de tantas medidas anunciadas que, se efetivadas, podem ser consideradas como retrocesso em relação aos direitos sociais, mesmo em tempos de crise, não se analisa cada um destes programas especificamente, tampouco se toma por base apenas um deles, mas se verifica o contexto geral da política e da economia brasileiras. O objetivo, portanto, não é uma tomada de posição ideológica e política contra o agora Presidente Michel Temer, mas uma análise da possibilidade, ou não, de retrocesso em relação aos direitos sociais efetivados por programas como os supracitados. Sendo que a discussão a respeito dos direitos sociais ainda é relevantíssima, principalmente em países que, em um período histórico recente, vivenciaram um regime ditatorial e um cenário de restrição de direitos, como o Brasil.

A contraposição crise $x$ efetivação dos direitos sociais também foi discutida no cenário econômico europeu recentemente e, a seguir, também analisar-se-á algumas das considerações lá realizadas, mas tecendo um contraponto com a crise brasileira, que representa muito mais uma crise institucional do que econômica. Será discutido, ainda, o fato de haver gastos e reajustes em outras esferas, mesmo no período de crise, enquanto há restrição em relação aos programas sociais.

No tocante à metodologia, parte-se da análise de um contexto específico - o do Brasil, com a crise vivenciada em 2016 e a tramitação do processo de Impeachment da Presidente Dilma Rousseff -, para, posteriormente, verificar a (im)possibilidade de retrocesso em relação aos direitos sociais em períodos de crise, de forma geral. Analisa-se, assim, o que é crise econômica por meio da obra de Schumpeter, diferenciando-a da crise institucional vivenciada no Brasil, assim como se aborda a posição de autores do direito constitucional para estudar o princípio da vedação ao retrocesso no tocante aos direitos sociais. Por fim, verifica-se a "exclusão" e a perda de identidade que essas restrições em relação aos programas sociais geram na sociedade brasileira. Não há a pretensão de se esgotar a temática discutida, assim como se espera que o presente trabalho desperte a consciência do leitor para a reflexão a respeito da efetivação dos direitos sociais prescritos no artigo 6으 da CR de 1988.

\section{CENÁRIO POLÍTICO-ECONÔMICO BRASILEIRO, AS MEDIDAS RESTRITIVAS DE DIREITOS SOCIAIS E A “CRISE” NO BRASIL EM 2016}

Primeiramente, importa destacar que, desde 2013, o cenário político e econômico brasileiro não tem sido favorável. Mais recentemente, ao assumir o governo em decorrência do trâmite do processo de Impeachment da Presidente Dilma Rousseff, Michel Temer anunciou diversas medidas entendidas como restritivas de direitos sociais garantidos à população. Logo nos primeiros dias, verificou-se a extinção de ministérios e a nomeação de Ministros apenas homens, brancos e muitos citados na Operação Lava-Jato. Dessa forma, por meio da Medida Provisória n. 726, de 12 de maio de 2016, Michel Temer acabou com o Ministério da Previdência Social e o transformou em uma Secretaria do Ministério da Fazenda, e, assim, a agenda de previdência social passou a se submeter 
à agenda econômica e do mercado. Também transformou a Controladoria Geral da União em um Ministério (artigo 8ํ, XVII, da Medida Provisória n. 726), extinguindo uma estrutura permanente de fiscalização e controle de todos os órgãos públicos e empresas estatais, na contramão da transparência governamental.

Além disso, as medidas foram contrárias ao seu plano de governo das eleições de 2014, enquanto vice-presidente de Dilma Rousseff. O Ministro provisório da Saúde defendeu a necessidade de reduzir o atendimento do Sistema Único de Saúde. (ABRASCO, 2016). O Ministro das Cidades revogou portaria que autorizava a construção de 11.250 casas do programa "Minha casa, minha vida"3 e uma das primeiras medidas tomadas pelo Ministro interino da Educação foi o contingenciamento dos recursos destinados ao Pronatec, ao Fies e ao Prouni. ${ }^{4}$ Por outro lado, no décimo-primeiro dia, sobraram recursos para reajustes das carreiras com os lobbies mais fortes. ${ }^{5}$

Com aproximadamente 30 dias de governo, anunciaram-se mudanças na aposentadoria, teto de gastos sociais, proibição de acumular benefícios, conforme amplamente divulgado pela mídia. Sobre as alterações relativas ao SUS que foram anunciadas, destaca-se que uma das primeiras afirmações do novo Ministro da Saúde foi sobre a suposta incapacidade do Estado em sustentar esse direito, chegando a afirmar que o SUS precisaria ser revisto, assim como a aconselhar os brasileiros a aderirem a planos de saúde privados. No tocante à Previdência Social, afirmou-se, sob o pretexto de um suposto rombo e da necessidade de se cumprir metas fiscais, que esta poderia sofrer alterações, como a ampliação do tempo de contribuição e da idade mínima para aposentadoria (SERRANO, 2016).

Convém lembrar, ainda, que, no início do governo de Michel Temer, a Comissão Interamericana de Direitos Humanos manifestou-se sobre tais anúncios, afirmando que constituem retrocesso no tocante aos direitos humanos. Também se posicionando contra "a designação de um gabinete de ministros que não inclui nenhuma mulher nem nenhum afrodescendente" e o anúncio de "aplicar uma redução dos fundos destinados aos programas sociais de habitação, educação e combate à pobreza" (OEA, 2016). Por fim, além das medidas anunciadas logo após o Impeachment, recentemente (fim de 2016), foi aprovada a PEC 241 (ou 55) na Câmara e no Senado, com o objetivo

\footnotetext{
${ }^{3}$ Conforme amplamente divulgado pela mídia em maio de 2016, a exemplo do Valor Econômico, disponível em: <http://www.valor.com.br/politica/4579501/governo-acabara-com-subsidios-baixa-renda-no-minha-casadiz-jornal>. Acesso em: 03.09.2016. Posteriormente, muito em função dos protestos realizados, em comunicado oficial constante no site do Portal Brasil, o Ministro afirmou que os cortes foram feitos pelo governo afastado e que o programa seria mantido.

${ }^{4}$ Também foi noticiado o corte nas bolsas de iniciação científica para graduação conforme notícia disponível em diversos sites de instituições de ensino superior, que receberam o informe na resposta do CNPq ao pedido de renovação dessas espécies de bolsa, a exemplo do Instituto Federal de Santa Catarina (2016).

${ }^{5}$ Sobre tais questões e com foco na questão do fim da escola pública debatida recentemente (WALLIN, 2016). Nesse sentido, inclusive, destaca-se que a Câmara aprovou pauta de R\$ 58 bilhões em reajustes e criação de 14.419 novos cargos, conforme amplamente divulgado na mídia nacional e internacional no início de junho de 2016. A exemplo da publicação no Jornal El País (CORTEZ, 2016).
} 
de congelar gastos (em áreas como saúde e educação), assim como assegurar um suposto controle da crise. ${ }^{6}$

Destaca-se que as medidas anunciadas decorrem de uma política de restrição orçamentária, em razão de uma suposta crise econômica vivenciada pelo Brasil. Por isso, torna-se necessário adentrar na esfera econômica e analisar o conceito de crise. Para tanto, o presente trabalho toma por base os ensinamentos de Joseph Schumpeter, que entende o desenvolvimento como um processo de mudança que descontinua as condições de equilíbrio pré-determinadas pelo modelo anterior. Isso ocorre por: 1. intermédio da introdução de um novo bem (com o qual os consumidores ainda não estão familiarizados) ou novo processo de produção; 2. abertura de um novo mercado ou conquista de nova fonte de matérias-primas; ou, ainda, 3. estabelecimento de uma nova organização da indústria. Estas novas combinações não são realizadas necessariamente pelas mesmas pessoas que controlam o processo produtivo ou comercial a ser deslocado pelo novo, o que explicaria características importantes do curso dos acontecimentos, especialmente numa economia de concorrência, na qual combinações novas signifiquem a eliminação das antigas pela concorrência. $O$ que explica o processo pelo qual indivíduos e famílias ascendem e decaem econômica e socialmente, assim como uma série de outros fenômenos do ciclo econômico, do mecanismo de formação de fortunas privadas, etc (SCHUMPETER,1988, p. 48-49).

Schumpeter trata da "destruição criativa", que constitui a essência do desenvolvimento econômico capitalista, no sentido de que os processos de criação e circulação estão em permanente mutação, promovendo uma contínua revolução por dentro das estruturas econômicas, mediante sistemática destruição das antigas estruturas e sua substituição por novas, a partir das inovações que vão surgindo. Desse modo, para o autor, o crescimento e o desenvolvimento nunca são contínuos no capitalismo, alternando-se uma sucessão periódica de crises e expansões, sendo que a origem de tais fenômenos está vinculada a todos os tipos de inovações. "É esse processo de permanente destruição criadora que constitui para Schumpeter a essência do desenvolvimento econômico capitalista", sendo que a referida revolução, não chega a ser contínua em si, mas tendendo ocorrer por surtos relativamente discretos, separados um dos outros por fases de relativa tranquilidade. $\mathrm{O}$ que permanece constante é a sucessão de ciclos de conjuntura, provocados pelo surgimento, difusão e absorção das inovações por meio da concorrência intercapitalista (SZMRECSÁNYI, 2006, p. 125).

\footnotetext{
6 "Os críticos afirmam que a PEC irá colocar limites em gastos que historicamente crescem todos os anos em um ritmo acima da inflação, como educação e saúde. Além disso, gastos com programas sociais também podem ser afetados pelo congelamento. Segundo especialistas e entidades setoriais, esta medida prejudicaria o alcance e a qualidade dos serviços públicos oferecidos. Especialistas apontam problemas para cumprir mecanismos já em vigor, como os investimentos do Plano Nacional de Educação. Aprovado em 2014, o PNE tem metas de universalização da educação e cria um plano de carreira para professores da rede pública, uma das categorias mais mal pagas do país. "A população brasileira está envelhecendo. Deixar de investir na educação nos patamares necessários, como identificados no PNE, nos vinte anos de vigência da emenda proposta - tempo de dois PNEs -, é condenar as gerações que serão a população economicamente ativa daqui vinte anos, a terem uma baixa qualificação", disse o consultor legislativo da Câmara dos Deputados, Paulo Sena, ao site Anped, que reúne especialistas em educação" (ALESSI, 2016).
} 
Para Schumpeter, a economia é capaz de se desenvolver com uma nova combinação (uma nova forma de produzir um bem já existente ou um novo produto, bem como a abertura de novos mercados), rompendo o fluxo circular do sistema econômico, desestabilizando-o e dando início a um novo sistema, modificado por tal inovação. Sendo que os booms econômicos, decorrentes da inovação, levam a crises, que, por sua vez, podem levar a depressões; destacando-se que as crises são importantes para firmar as inovações bem-sucedidas e descartar as que são ineficientes. "Assinala que o desenvolvimento econômico nunca tem início onde parou após uma crise, pois o seu acontecimento modificará permanentemente o sistema". (ARAÚJO; FERREIRA JUNIOR, 2016, p. 18). ${ }^{7}$ Desse modo, apesar da heterogeneidade das diferentes crises econômicas, o autor trouxe uma linha de raciocínio geral aplicável para explicar as crises, sendo estas essenciais para o capitalismo e para o surgimento das inovações (ARAÚJO; FERREIRA JUNIOR; 2016, p. 8; 15-18).

Nesse contexto, em que as crises são fenômenos recorrentes e essenciais ao capitalismo, a naturalidade dessas crises cíclicas exigiria do estado a autonomia de implantar medidas anticíclicas, sob o viés keynesiano, como já ocorreu em outros momentos, valendo-se do aumento da dívida pública. Nesse mesmo sentido, poderia se pensar em medidas anticíclicas (como foi o próprio PAC Programa de Aceleração de Crescimento), para combater a crise, ou seja, para amenizar os efeitos do ciclo econômico, encurtando os períodos de crise com medidas como a redução de tributos, a expansão do crédito para produção e o aumento dos gastos públicos, realizando-se investimentos capazes de estimular a economia através da geração de renda e emprego para a base da população. Ou seja, o aumento do déficit público deve se expandir de modo a restabelecer o equilíbrio econômico.

Contudo, as medidas anunciadas pelo governo atual não se constituem em "medidas anticíclicas" com o objetivo de atingir o equilíbrio nos intervalos da crise cíclica. Pelo contrário, são medidas de restrição orçamentária, na tentativa de aumentar o superávit primário (economia para pagamento dos juros da dívida) e gerar o pagamento da dívida bruta, mas que geram apenas cortes em programas sociais, não estimulando o crescimento e o desenvolvimento - a exemplo do corte no programa "Minha casa, minha vida", que promovia o aumento do emprego na construção civil. O que se denomina de "contingenciamento" ou "bloqueio de despesas" anunciado no final do governo de Dilma Rousseff e (prevendo um "rombo" ainda maior) no governo de Michel Temer, é uma tentativa de atingir a meta fiscal (economia para pagamento dos juros da dívida) fixada pelo Congresso para 2016. No entanto, também não há anúncios de medidas efetivas em relação ao superávit secundário, quando há receita para investimentos. E ainda há que se considerar que a dívida brasileira representa um percentual no PIB muito inferior ao de diversos países (CALEIRO, 2015), sendo a medida de contingenciamento questionável, também do ponto de vista econômico.

Ademais, tais medidas estão na contramão da autonomia do Estado em relação à elaboração de políticas públicas. Deve-se lembrar que o Estado, além de garantir direitos básicos, atua como

\footnotetext{
${ }^{7}$ Sobre a mudança em relação ao conceito de crise após Marx, verificar: SCHUMPETER, Joseph A. Capitalismo, socialismo e democracia. Rio de Janeiro: Fundo de Cultura, 1961.
}

Revista do Direito [ISSN 1982-9957]. Santa Cruz do Sul, v. 3, n. 53, p. 2-22, set./dez. 2017. https://online.unisc.br/seer/index.php/direito/index 
interventor na economia, na tentativa de diminuir esses períodos de crise por meio de medidas anticíclicas, e, quando se retira este poder do Estado, tais crises são inevitavelmente prolongadas. E, ainda, diferentemente do cenário de crise cíclica retratado por Schumpeter, no caso brasileiro a crise também é "institucional" (com reflexos na economia), no que diz respeito ao Estado, tendo em vista que as medidas anunciadas fecham um ciclo de políticas intervencionistas, anticíclicas e de pleno emprego, para inaugurar um Estado voltado para a austeridade e restrição orçamentária. Além disso, o mais preocupante é que uma enorme fatia da população não reconhece a legitimidade do governo de Michel Temer, constituindo-se em verdadeiro grupo heterogêneo que realizou as ocupações no Ministério da Cultura e protagoniza os protestos nas ruas contra o Presidente. ${ }^{8}$

Portanto, é preciso analisar, sob a ótica jurídica, o tratamento dado aos direitos sociais no Brasil e se tais restrições em políticas e programas sociais seriam ou não permitidas em períodos de crise, diante do rol de direitos sociais prescritos na Constituição da República de 1988, verificando-se a posição dos constitucionalistas pátrios e estrangeiros. Inclusive, deve-se considerar o cenário brasileiro extremamente peculiar de "crise", no qual se realiza cortes nos programas que efetivam direitos sociais, diversas são as regalias para políticos, assim como houve aumento para os servidores federais recentemente, conforme se verificou acima.

\section{OS DIREITOS SOCIAIS E O PRINCÍPIO DA VEDAÇÃo AO RETROCESSO EM PERÍODOS DE CRISE}

No contexto histórico após a Segunda Guerra Mundial, na Europa, houve a transição de regimes autoritários para regimes democráticos, com um maior reconhecimento de direitos, mormente dos denominados direitos sociais. Conforme preceitua Juan Ramón Capella, "el calificativo de sociales se aplica a ciertos derechos de uma razón de historia cultural", destacando que com o seu reconhecimento se pretendeu adiar ou neutralizar a questão social. Os direitos adjetivados como sociais, foram reconhecidos pela confluência dos jogos de forças diferentes sobre os objetivos que podiam ser coincidentes com determinadas políticas reformistas (CAPELLA, 2001).

No Brasil, a primeira Constituição que apresentou os direitos sociais como questão fundamental do Estado foi a de 1934. Esta foi fruto do processo de reconstitucionalização, resultado de um paradigma de modernização conservadora imposto pelas emergentes condições da Revolução de 1930. No entanto, as diretrizes liberal-reformistas não acompanhavam o grau de determinadas conquistas como estas - ainda se resguardava princípios do velho federalismo republicano e do regionalismo liberal elitista: as massas trabalhadoras, por exemplo, não tinham garantias e instrumentos para colocar em prática tais direitos (WOLKMER, 1989, p. 137-141).

Dessa forma, Antônio Carlos Wolkmer alerta para a maneira com a qual esses direitos apareceram em nosso ordenamento jurídico, o que não ocorreu de forma espontânea e acabada mediante processos democráticos, lutas populares e avanços da sociedade civil, mas foi resultado de

\footnotetext{
${ }^{8}$ Em razão de tais manifestações, em um primeiro momento, hesitou-se em anunciar as reformas trabalhistas e previdenciárias desejadas pelo mercado, assim como se recriou o Minc e alguns ministros investigados foram afastados. (PINTO NETO, 2015)
}

Revista do Direito [ISSN 1982-9957]. Santa Cruz do Sul, v. 3, n. 53, p. 2-22, set./dez. 2017. https://online.unisc.br/seer/index.php/direito/index 
oposições e resistências, concessões e favores no jogo das velhas elites oligárquicas. Destaca que inexiste uma tradição participativa de base popular-burguesa na evolução político-jurídica brasileira, pois o constitucionalismo brasileiro (político ou social), tem sido produto da "conciliação-compromisso" entre "o autoritarismo social modernizante" e o "liberalismo burguês conservador" (WOLKMER, 1989, p. 142).

Apenas posteriormente (Constitucionalismo Social), verifica-se a democracia social, o intervencionismo estatal e a crescente proletarização das massas. (WOLKMER, 1989, p. 52). O Estado Social, protetor desses direitos, de acordo com Paulo Bonavides, aí está para produzir as condições e os pressupostos fáticos indispensáveis ao exercício dos direitos fundamentais e, para tal, não há outro caminho senão reconhecer o estado atual de dependência do indivíduo em relação às prestações do Estado, assim como fazer com que este cumpra "a tarefa igualitária e distributivista sem a qual não haverá democracia nem liberdade". Inclusive, é por meio da efetivação dos direitos sociais básicos que se realiza a igualdade na sociedade: uma igualdade que nivela, voltada para situações humanas concretas, "operada na esfera fática propriamente dita e não em regras abstratas ou formais de Direito", sendo que, por igualdade material, entende-se que o Estado se obriga mediante intervenções de retificação na ordem social a remover as mais profundas e perturbadoras injustiças sociais (BONAVIDES, 2007, p. 378-379).

Ou seja, os direitos sociais, também denominados direitos de segunda dimensão, são direitos fundamentais que exigem atuação positiva do Poder Público e objetivam implementar a igualdade social ou a igualdade material. Há várias espécies de direitos sociais que são agrupados em algumas categorias: os direitos sociais dos trabalhadores; os direitos sociais da seguridade social; os direitos sociais de natureza econômica; os direitos sociais da cultura; os de segurança. Inclusive, os beneficiários destes direitos sociais são todos os indivíduos, mas em especial aqueles que necessitam de um amparo maior do Estado.

Como observa Daniel Hachem, o que diferencia um direito qualquer de um direito fundamental é o regime jurídico ao qual ele está submetido e que the empresta uma proteção reforçada contra ações e omissões do Estado e dos sujeitos privados. Na Constituição brasileira, o autor destaca dois elementos deste regime especial: a aplicabilidade imediata (artigo $5^{\circ}$, $\S 1^{\text {ㅇ) }}$ e a proteção contra reformas constitucionais abolitivas (artigo 60, $\S 4^{\circ}$, IV). Também gozam de características peculiares, como a multifuncionalidade e a dupla dimensão (objetiva e subjetiva), "compelindo o Estado não apenas a atender as demandas individualizadas ou coletivas que the sejam exigidas pelo cidadão, mas também a criar estruturas organizativas e procedimentais que viabilizem a sua fruição universalizada", assim como normas de proteção que proporcionem a sua tutela contra violações pelos particulares. Por fim, a sua restrição pelo legislador subordina-se uma série de critérios rigorosos que objetivam salvaguardar a intangibilidade de seu núcleo essencial, como o dever de respeito ao princípio da proporcionalidade e da razoabilidade - no caso dos direitos sociais, o princípio da proibição de retrocesso social (HACHEM, 2014).

Felipe Derbli, em obra específica sobre o princípio da vedação ao retrocesso, ressalta o seu elemento positivo, no sentido do dever de o legislador manter-se no propósito de ampliar, progressivamente, de acordo com as condições fáticas e jurídicas, o grau de concretização dos 
direitos fundamentais sociais, por meio da garantia de proteção dessa concretização à medida que nela se evolui: é a "obrigação de avanço social" (DERBLI, 2007. p. 202). Este princípio da vedação ao retrocesso dos direitos sociais foi desenvolvido na Alemanha e em Portugal, partindo da constatação de que ao dever positivo do Estado existe uma imposição de abstenção, ou seja, este não poderia adotar medidas que flexibilizem as conquistas alcançadas na seara dos direitos sociais. ${ }^{9} \mathrm{Na}$ Alemanha dos anos setenta do século passado, quando a crise econômica punha em cheque a possibilidade de progredir indefinidamente nos benefícios sociais proporcionados pelo Estado social ou fazia duvidar, simplesmente, da possibilidade de os manterem inalterados, é que se desenvolveu a discussão doutrinária e jurisprudencial acerca dos limites que o princípio constitucional do Estado social colocaria a uma intervenção legislativa que afetasse os benefícios outrora concedidos.

A teoria da "irreversibilidade" ou da "proibição do retrocesso" constituiria a referência chave desse debate, encerrando em si mesma a ideia de que as realizações do Estado social, apoiadas que estavam no correspondente princípio diretivo constitucional (o artigo 20, item 1, da Constituição alemã que define a Alemanha como Estado social, e o artigo 28, item 1, que vincula os Estados federados ao princípio do Estado do Direito social), estariam constitucionalmente protegidas contra eventuais retrocessos que as afetassem no seu conteúdo essencial, destacando-se que a Constituição alemã não previa, entretanto, um rol de direitos sociais (NOVAIS, 2010, p. 240).

$\mathrm{E}$, partindo desse contexto histórico, há autores que se posicionam contrariamente ao princípio da vedação ao retrocesso, como Jorge Reis Novais, para quem, a ideia de realização progressiva dos direitos sociais só faria sentido quando se leva em conta a natureza especial deste tipo de direitos, ou seja, de que são direitos sujeitos a uma reserva do financeiramente possível, cuja realização não é possível nem exigível. O autor questiona, então, de onde se retiraria a ideia de que os recursos disponíveis serão mais amanhã e por que razão não poderia haver situações momentâneas de crise econômica ou até de penúria. Ademais, afirma que a diminuição dos níveis de acesso de um determinado grupo ou camada de população a um certo benefício pode ser justificada pelo aumento dos níveis de acesso de um outro grupo ou camada social ao mesmo ou a um outro direito social. Questiona, ainda, qual seria o critério constitucional para definir materialmente o sentido de retrocesso, afirmando que, na sua dimensão negativa, os direitos sociais passariam (através da proibição da sua afetação negativa após concretização legal), a usufruir de um grau de proteção e garantia não conferidas aos direitos de liberdade. Por esses motivos, o autor não atribuiu à proibição de retrocesso o status de princípio jurídico ou de valor constitucional. (NOVAIS, 2010, p. 243-245).

\footnotetext{
${ }^{9}$ Neste sentido, o acórdão n. 39/84 da Corte Constitucional Portuguesa, que declarou a inconstitucionalidade de uma lei que havia revogado boa parte da Lei do Serviço Nacional de Saúde, sob o fundamento de que com esta revogação estava o legislador atentando contra o direito constitucional à saúde prescrito no artigo 64 da Constituição portuguesa: "[...] Que o Estado não se dê a devida realização às tarefas constitucionais, concretas e determinadas, que lhe está cometida, isso só poderá ser objecto de censura constitucional, em sede de inconstitucionalidade por omissão. Mas, quando desfaz o que já havia sido realizado para cumprir a tarefa, e com isso atinge uma garantia de um direito fundamental, então a censura constitucional já se coloca no plano da própria inconstitucionalidade por acção". Esta posição foi reafirmada no Acórdão 509/2002.
} 
Inclusive, para o autor, deve-se tratar o problema sob a óptica da teoria da restrição aos direitos fundamentais. ${ }^{10}$

No entanto, conforme adiante se verá com maior vagar, no presente trabalho, no cenário brasileiro, defende-se o princípio da vedação ao retrocesso, com fundamento no princípio da confiança e na dignidade da pessoa humana, assim como porque há previsão expressa de direitos sociais na Constituição pátria. Assim como se sustenta (seja pela ótica da vedação ao retrocesso ou pela lente da teoria da restrição dos direitos fundamentais) a impossibilidade de cortes nos programas sociais apontados no primeiro tópico, principalmente pelas peculiaridades inerentes à "crise" brasileira, em muito distanciadas da realidade europeia. Até porque, diferentemente do critério adotado por Jorge Reis, no Brasil, os cortes em programas sociais não são realizados para a efetivação ou acesso de direitos de alguma outra camada da população.

Dessa forma, em defesa do princípio da vedação ao retrocesso, primeiramente, ressalta-se que a premissa deste princípio guarda íntima relação com a noção de segurança jurídica. Assim, no âmbito do pensamento constitucional contemporâneo, a doutrina tem considerado a segurança jurídica como expressão inarredável do Estado de direito. A garantia de uma certa estabilidade das relações jurídicas e da própria ordem jurídica se encontra umbilicalmente vinculada também à própria noção de dignidade da pessoa humana. Com efeito, "a plena e descontrolada disponibilização dos direitos e dos projetos de vida pessoais por parte da ordem jurídica acabaria por transformar os mesmos (e, portanto, os seus titulares e autores) em simples instrumento da vontade estatal" (SARLET, 2010, p. 433-434). Assim, não se pode ofender os postulados básicos inerentes ao princípio do Estado Social de Direito e aos direitos fundamentais.

Inclusive, Ingo Wolfgang Sarlet identifica que ambas as ordens jurídicas, alemã e brasileira, há uma vedação (pelo menos relativa) de retrocesso na esfera do sistema vigente de prestações sociais, que, em última análise, representa a concretização no plano da legislação infraconstitucional do princípio do Estado Social de Direito e/ou dos direitos fundamentais sociais consagrados na Constituição" (SARLET, 2007, p. 17). O autor ressalta que, diferentemente da Alemanha, no sistema pátrio, a Constituição da República de 1988 foi pródiga em direitos fundamentais sociais, caracterizados pela fundamentalidade material e formal, que assegura aos mesmos um grau diferenciado e evidentemente mais elevado de proteção. E conclui que no sistema pátrio também é possível sustentar a existência de uma proibição de retrocesso na esfera social, ainda que não possa assumir feição absoluta. E esta previsão expressa de direitos sociais na Constituição brasileira é mais

\footnotetext{
${ }^{10}$ Nas palavras do autor: “... porquê, pura e simplesmente, não tratar o retrocesso por aquilo que, na realidade, é, ou seja, restrição a direito fundamental, legítima ou ilegítima consoante se observam ou se desrespeitam os limites constitucionais das restrições aos direitos fundamentais? Porquê não resolver o aparentemente inextricado problema da defesa dos direitos sociais tão somente recorrendo à teoria das restrições aos direitos fundamentais, desenvolvida, testada e utilizada generalizadamente em Estado de Direito há mais de cinquenta anos? Que tal não pudesse ou não possa ser feito na Alemanha, percebe-se: a teoria das restrições aos direitos fundamentais não podia ser utilizada nas restrições aos direitos sociais pura e simplesmente porque estes não eram e não são, na ordem constitucional alemã, direitos fundamentais. Sentida, porém, a necessidade constitucional de os defender, havia que inventar algo, no caso, com grande sucesso, a ideia e a fórmula de proibição do retrocesso. Trata-se, portanto, de uma invenção alemã, naturalmente aplicável em contextos jurídicos semelhantes, mas totalmente improdutiva, redundante e obscurecedora em contextos constitucionais em que os direitos sociais são direitos fundamentais..." (NOVAIS, 2010, p. 246-247).
} 
robusta que as soluções desenvolvidas à luz da Lei Fundamental da Alemanha, carente de direitos fundamentais sociais e de norma expressa consagrando o respeito aos direitos adquiridos (SARLET, 2007, p. 18).

Além disso, para Adriana Schier, a proibição do retrocesso é tomada como um princípio que assegura que a densificação dos direitos sociais feita pela legislação infraconstitucional seja protegida contra a ação do legislador futuro. A autora defende a fundamentalidade dos serviços públicos, pelo seu conteúdo e sua importância (cláusula de abertura do artigo $5^{\circ}$, $\S 2^{\circ}$, da Constituição), e, consequentemente, a incidência da vedação ao retrocesso. Isso porque, os direitos fundamentais e a dignidade da pessoa humana são instrumentalizados por serviços públicos. Defende, assim, que a definição do serviço público adequado, pelo legislador, criou, para os cidadãos, o direito subjetivo ou algumas posições jurídicas de vantagem, de que o Estado preste diretamente (ou por meio de seus delegados), de forma contínua e mediante módica contraprestação (SCHIER, 2009, p. 197-198). ${ }^{11}$

A proibição de retrocesso funciona como instrumento que permite proteger a regulamentação infraconstitucional dos direitos fundamentais. Isto é, a partir de sua aplicação, o conteúdo das leis que concretizam tais direitos não poderá ser validamente revogado sem substitutivos compensatórios. Dessa forma, não se poderá admitir que o legislador venha a reduzir, ao menos de forma arbitrária ou desproporcional o patamar de desenvolvimento infraconstitucional de um direito fundamental social. As leis que regulam os direitos fundamentais previstos na Constituição criam direitos subjetivos na exata dimensão estabelecida pelo legislador, protegida contra qualquer redução arbitrária. Portanto, a proibição de retrocesso atua como complemento necessário capaz de aperfeiçoar o sistema de proteção dos direitos fundamentais. (SCHIER, 2009, p. 197-198)

De acordo com José Joaquim Gomes Canotilho, os direitos sociais e econômicos, uma vez obtido certo grau de realização, passam a constituir, simultaneamente, uma garantia institucional e um direito subjetivo. Sendo que o princípio da proibição do retrocesso encontra justificativa na proteção da confiança dos cidadãos e do núcleo essencial dos direitos sociais. (CANOTILHO, 2000, p. 338). Assim, tomado como princípio do retrocesso social, terá como núcleo essencial a proibição de que o legislador infraconstitucional revogue lei que, ao densificar direitos fundamentais, tenha criado, para os cidadãos, situações de vantagem capazes de garantir a máxima efetividade das normas constitucionais. Desse modo, a vedação ao retrocesso decorre diretamente dos princípios fundamentais, notadamente da dignidade da pessoa humana. Inclusive, determinados conteúdos exigidos pelo legislador ordinário, acabam por alcançar um grau de consenso social tal que são aceitos pela sociedade como complemento necessário dos direitos fundamentais previstos na Constituição. E apesar da natureza de princípio (aqui compreendida de acordo com a teoria de Alexy), dependendo a sua aplicação de um juízo de ponderação em cada caso concreto, "admite-se que o núcleo essencial do princípio em questão reside na proibição dirigida ao legislador ordinário de

\footnotetext{
${ }^{11} \mathrm{E}$ ainda: Patryck de Araújo Ayala trata da questão da proibição de retrocesso na esfera do direito ambiental, tratando com fundamento na cláusula de progressividade na implementação dos direitos sociais, econômicos e culturais, defendendo que "uma cláusula de progressividade não expõe apenas um imperativo de progresso no desenvolvimento humano, senão de progresso no desenvolvimento das condições que sejam essenciais à viabilidade e à durabilidade de todas as formas de vida" (AYALA, 2011).
} 
revogar normas cujos conteúdos tenham condensado direitos fundamentais". (SCHIER, 2009, p. 158164). ${ }^{12}$ No mesmo sentido, Luísa Cristina Pinto e Netto concorda que o núcleo essencial dos direitos sociais deve ser preservado e também faz menção à ponderação ${ }^{13}$ (NETTO, 2016, p. 611-618).

Portanto, o conteúdo do mínimo existencial referido pela doutrina como limite para a vedação ao retrocesso, está relacionado à garantia de prestações básicas que permitam a todos os cidadãos viver dignamente. Assim, "identifica-se o mínimo existencial como as condições básicas exigidas para que os homens, mulheres e crianças possam usufruir do catálogo de direitos fundamentais", que indicam os valores que norteiam cada nação social politicamente organizada. Ou seja, "trata-se do elenco de situações materiais que permite a todo e qualquer indivíduo reconhecer-se como um sujeito dotado de dignidade". ${ }^{14}$ Nesse sentido, os programas apontados no primeiro tópico do presente trabalho, que são objeto de medidas de restrição anunciadas pelo atual governo, garantem esse mínimo existencial e possibilitam a sobrevivência digna das pessoas que deles dependem. E, por isso, devem ser mantidos.

E como afirma Ingo Wolfgang Sarlet, o princípio fundamental da proibição (relativa) de retrocesso na esfera social, "seja ele implementado por meio do reconhecimento de cláusulas pétreas, seja desenvolvido implicitamente a partir de outros princípios constitucionais", constitui-se em salvaguarda do Estado social de Direito, assim como da justiça material, mas principalmente da dignidade da pessoa humana, "valor-guia de toda a ordem constitucional" e objetivo permanente de uma ordem jurídica que se pretenda legítima (SARLET, 2010, p. 20).

Nessa toada, importa destacar a posição de Emerson Gabardo, que ressalta a dignidade como ponto de partida para a justificação dos fins do Estado, afirmando que o ponto de chegada é o

\footnotetext{
${ }^{12}$ Sobre a ponderação, assim preceitua Ingo Wolfgang Sarlet: "Outro aspecto que merece ser destacado é o fato de que a amplitude e intensidade da proteção outorgada pela ordem constitucional às posições jurídicosubjetivas na esfera social, tanto no plano constitucional, quanto ao nível da legislação ordinária, dependem de uma análise centrada nas especificidades do caso concreto, exigindo um procedimento tópico-sistemático, já que nos parece inviável o estabelecimento de critérios abstratos e genéricos, a não ser o próprio reconhecimento de uma proibição meramente relativa de retrocesso." E assim continua o autor sobre a proporcionalidade: "Também pode ser tida como paradigmática a utilização do princípio da proporcionalidade como critério aferidor da legitimidade de uma restrição na esfera de uma proibição de retrocesso social, revelando, neste contexto, que a função do referido princípio, igualmente deduzido do princípio do Estado de Direito, não se limita a servir de parâmetro para o exame da constitucionalidade das leis restritivas de direitos fundamentais, incluídos neste rol os assim denominados direitos sociais. Com efeito, também a ação erosiva do legislador que tenha por objetivo a implementação de ajustes e cortes no âmbito do sistema infraconstitucional de prestações sociais deve levar em conta as exigências do princípio da proporcionalidade, isto é, ser ao mesmo tempo necessária, adequada e razoável, pena de ofensa aos próprios direitos fundamentais sociais e ao princípio do Estado social de Direito. Em última análise, não se poderá abdicar jamais da tarefa de realizar uma cuidadosa ponderação de todas as circunstâncias, de modo especial entre o valor dos direitos dos particulares a determinado grau de segurança social e os reclamos do interesse da coletividade." (SARLET, 2010, p. 19-20).

13 Para a autora, não se deve retirar do sistema jusfundamental nenhum conteúdo dotado de fundamentalidade material, devendo-se realizar a ponderação e verificar se eventual restrição é constitucionalmente legítima, questionando-se o seu objetivo. (PINTO e NETTO, 2010, p. 167).

${ }^{14}$ Por isso, Adriana Schier entende que o regime jurídico do serviço público, naquilo que se refere ao mínimo existencial - universalidade, modicidade das tarifas e continuidade das prestações, está protegido pela cláusula de proibição de retrocesso social. "Ou seja, deve considerar-se constitucionalmente garantido, sendo inconstitucionais quaisquer medidas estaduais que, sem a criação de outros esquemas alternativos ou compensatórios, se traduzam, na prática, numa anulação, revogação ou aniquilação pura e simples desse núcleo essencial (SCHIER, 2009, p. 166-168).
}

Revista do Direito [ISSN 1982-9957]. Santa Cruz do Sul, v. 3, n. 53, p. 2-22, set./dez. 2017. https://online.unisc.br/seer/index.php/direito/index 
"desenvolvimento da personalidade", que compreende, necessariamente, a ideia de felicidade como determinante oficial da atuação do Estado. "Um modelo de Estado social que garanta direitos fundamentais precisa superar a noção de dignidade rumo à de felicidade, a partir de uma ideia de sobreposição e não de abandono", pois não seria possível, sob a ótica política-jurídica, aceitar a ideia de um ser humano indigno, porém, feliz. Deve-se ter em mente, ainda, que o princípio da dignidade fomentou o direito do pós-guerra e se constitui em uma das bases do princípio republicano, como no Estado de Direito. "A dignidade é o sustentáculo primário, não o único, da ideia de direitos fundamentais quando se está sob o manto de um modelo de Estado social, cujo regime é marcadamente interventor" (GABARDO, 2009, p. 331). ${ }^{15}$

No caso brasileiro, os direitos sociais são considerados direitos fundamentais, expressamente previstos no rol do artigo 6ํㅜ da Constituição da República, diferentemente do caso da Alemanha na época do surgimento da teoria da vedação ao retrocesso. E a Constituição da República de 1988 prescreve, em seu artigo 3o, os objetivos fundamentais da República Federativa do Brasil: garantir o desenvolvimento nacional, a construção de uma sociedade livre, justa e solidária, a erradicação da pobreza e da marginalização, e a redução das desigualdades sociais e regionais. Isto é, tem-se uma norma constitucional de eficácia vinculante que garante o tratamento solidário e progressista ("desenvolvimento"), de onde se extrai a impossibilidade de retrocesso em relação aos direitos fundamentais sociais prescritos na Constituição, verdadeiros vetores de interpretação do princípio da vedação ao retrocesso.

Dessa forma, seja pela proibição de retrocesso, ou pela ótica da teoria da restrição aos direitos fundamentais, considerada por Jorge Reis Novais, no Brasil, não há como se sustentar as diversas violações aos direitos fundamentais que vêm sendo anunciadas no atual cenário políticoeconômico brasileiro, pelos seguintes motivos: a) entende-se pela aplicabilidade imediata das normas garantidoras de direitos sociais, e, como se verificou acima, há previsão na Constituição a respeito da dignidade da pessoa humana e do tratamento igualitário e solidário para todas as pessoas; b) eventuais cortes no Brasil não ocorrem para a efetivação de outro benefício para outro grupo ou camada social ou mesmo para que seja efetivado outro direito social para o mesmo grupo; c) os cortes anunciados são contrários ao próprio programa de governo de Michel Temer quando eleito como vice-presidente de Dilma Rouseff; d) os mencionados cortes nos programas sociais ocorrem de forma paralela aos aumentos de servidores federais e ao desvio de dinheiro em esquemas de corrupção, verificando-se forte motivação ideológica e econômica, não havendo razão para retrocesso ou para restrição.

\footnotetext{
${ }^{15} \mathrm{E}$ sobre a opção constitucional a respeito da dignidade e da felicidade assim preceitua: "Esta opção constitucional de serem amalgamados a dignidade e a felicidade é adequada considerando que tais fundamentos, em conjunto, remetem-se a um princípio ético aglutinador, que é o do humanismo republicano. Isso ocorre porque o poder em uma república tem caráter exclusivamente instrumental, o que exige o máximo, seja dos representantes detentores de mandato, seja daqueles que receberam função pública por intermédio dos outros mecanismos jurídicos de escolha dos agentes estatais. Não basta que o Estado, por intermédio dos representantes do povo, garanta o mínimo relativo à dignidade de todos, pois isso expressaria apenas um cumprimento parcial das obrigações tipicamente republicanas. Mais do que reconhecer a idéia tipicamente democrática da dignidade, é preciso ressaltar a idéia republicana de felicidade, que, embora não mencionada expressamente pelo constituinte, é decorrência inexorável da sistemática constitucional" (GABARDO, 2009, p. 341-344).
}

Revista do Direito [ISSN 1982-9957]. Santa Cruz do Sul, v. 3, n. 53, p. 2-22, set./dez. 2017. https://online.unisc.br/seer/index.php/direito/index 
Portanto, deve-se privilegiar a dignidade da pessoa humana e a manutenção de programas sociais que garantem os direitos mais básicos para a sobrevivência humana, como alimentação, moradia, saúde e educação. ${ }^{16}$ Nesse contexto, também se faz necessário destacar as palavras de Adriana Schier a respeito do que a doutrina denomina de "reserva do possível", segundo a qual, "se a metáfora do cobertor curto deve ser considerada para se exigir, do poder público, aquilo que for razoavelmente possível", não poderá jamais, em um Estado Democrático de Direito, desobrigar a Administração de demonstrar a inexistência de recursos capazes de suportar os custos financeiros para garantir, a todos, o mínimo existencial. E, ainda, é ônus do poder público comprovar a correta utilização dos recursos, em consonância com os fins constitucionais. Isto é, pode-se comprovar a inexistência de recursos para tudo o que se faça necessário para determinada sociedade, mas se deve comprovar que aqueles que existiam foram utilizados segundo as prioridades jurídicas estabelecidas na sistemática constitucional. Assim, a autora defende que o reconhecimento da proibição do retrocesso em relação às conquistas sociais promovidas pela regulamentação dos serviços públicos, garantindo-se a prestação do serviço público adequado, é um bom instrumental "que permite auxiliar no encontro de um dos caminhos possíveis a ser trilhado para o alcance do almejado Estado necessário". (SCHIER, 2009, p. 172-173)

Isto é, não há que se falar na "reserva do possível", quando esta ausência de recursos decorre da má-gestão de recursos existentes. Ademais, a questão do retrocesso na esfera dos direitos sociais em períodos de crise também foi discutida na Europa nos períodos recentes de crise econômica, quando, inclusive, chegou-se a defender que poderia sim haver tal retrocesso, tendo em vista a indisponibilidade de recursos financeiros para efetivá-los.

Na seara de tal discussão, Paula Garcia Peraza ressalta que, na crise europeia, não se focou nos direitos humanos ou individuais, mas apenas em medidas de austeridade. Destacando-se que o Comitê Europeu advertiu aos Estados signatários da Convenção Internacional dos Direitos Econômicos, Sociais e Culturais sobre a necessidade de respeitar e proteger as obrigações do Pacto, mesmo em tempos de recessão. Apesar da autoridade nacional para decidir as questões referentes aos direitos sociais, o Comitê advertiu que havia a necessidade de se seguir quatro requisitos: temporariedade, necessidade e proporcionalidade, não discriminação e proteção do mínimo referente a núcleo essencial de direitos, sendo estes requisitos relacionados à proibição retrocesso (PEDRAZA, 2014, p. 64-65).

A autora chega à conclusão de que priorizar a austeridade econômica na crise europeia não era a única saída, mas sim questão ideológica. Inclusive destaca que os grupos prejudicados não participaram das decisões, assim como não houve um embasamento nos direitos humanos enfatizando que diferentes medidas de austeridade implementadas na Grécia, em Portugal e na Espanha foram declaradas contrárias aos direitos econômicos e sociais ou inconstitucionais. Por isso, ressalta a autora (PEDRAZA, 2014, p. 65-67), é necessário reforçar a democracia e a participação individual na política, concluindo que a austeridade tem como característica um impacto de retrocesso

16 Inclusive, o Supremo Tribunal Federal, inclusive, reconheceu a vedação ao retrocesso no julgamento de questão referente às vagas na creche e na Pré-escola para crianças com até cinco anos de idade. BRASIL. ARE 639337 AgR, Relator(a): Min. CELSO DE MELLO, Segunda Turma, julgado em 23/08/2011, DJe-177 DIVULG 1409-2011 PUBLIC 15-09-2011 EMENT VOL-02587-01 PP-00125.

Revista do Direito [ISSN 1982-9957]. Santa Cruz do Sul, v. 3, n. 53, p. 2-22, set./dez. 2017. https://online.unisc.br/seer/index.php/direito/index 
nos direitos econômicos e sociais e também no coração da Europa, que é o Estado de Bem-Estar Social. Em vista disso, defende que é urgente e necessário reforçar os mecanismos de proteção. ${ }^{17}$

A mesma ideia pode ser trazida para o contexto brasileiro, devendo-se ter em mente que não há como justificar os cortes em diversos programas sociais sob a justificativa de que há crise econômica se, em paralelo, reajustam-se os salários de servidores federais, por exemplo. Além disso, as investigações amplamente divulgadas na mídia dão conta de diversos escândalos de corrupção e desvio de dinheiro, inclusive por integrantes do próprio governo atual, pós-Impeachment.

Portanto, as medidas anunciadas pelo governo atual estão na contramão da efetivação dos direitos sociais e se constituem em verdadeiro retrocesso em relação às garantias já conquistadas. Ou seja, são medidas de restrição orçamentária, que geram apenas cortes em programas sociais, não estimulando o crescimento e o desenvolvimento do país, sob o ponto de vista econômico. A crise brasileira também é "institucional", no que diz respeito ao Estado, tendo em vista que as medidas anunciadas fecham um ciclo de políticas intervencionistas, anticíclicas e de pleno emprego, para inaugurar um Estado voltado para a austeridade e restrição orçamentária.

Em termos claros, há crise apenas para a efetivação dos direitos sociais, a justificar inúmeros cortes nos mais diversos programas sociais para a população que deles mais necessita. Por tais motivos, o argumento da ausência de recursos financeiros não cabe no cenário brasileiro, isto é, o que causa o déficit nas contas públicas e um possível não alcance da meta fiscal é a má gestão do dinheiro público, e não os gastos com programas sociais. Os prejuízos da "crise" são suportados pelas mesmas camadas, as que solidarizam o prejuízo sem participação no lucro do Estado capitalista.

\section{A EXCLUSÃO GERADA PELO RETROCESSO NOS PROGRAMAS SOCIAIS}

A questão da vedação ao retrocesso e dos direitos sociais no Brasil, principalmente diante das escolhas anunciadas pelo Executivo e pelo Legislativo atuais, no sentido de restrição dos direitos sociais, anunciadas no primeiro tópico, leva a questionamentos mais profundos na seara filosófica.

Para tanto, há que se destacar as lições do filósofo alemão Jurgen Habermas, que estudou a democracia desde o início de suas pesquisas, desde a democracia deliberativa, que acabou por conduzi-lo ao seu segundo trabalho sobre a teoria da ação comunicativa, ou seja, do agir comunicativo. "Que tipo de ação nos move cada dia?" Parte-se da ideia de que a democracia se funda no entendimento entre as pessoas, e este entendimento só é possível se cada ser humano estiver aberto para ouvir e entender o outro. Esse entendimento pode ser alcançado através de algo que todos os seres humanos possuem: a razão, podendo-se discutir apenas se houver igualdade entre as pessoas, não imposição. É por meio da comunicação que se consegue chegar a um consenso para se incluir o outro. "O procedimento democrático fundamenta uma suposição de racionalidade, no sentido que acena com resultados neutros", isto é, imparciais, pois a racionalidade

\footnotetext{
17 Destaca-se que o Brasil é signatário do Pacto Internacional sobre Direitos Econômicos, Sociais e Culturais (desde 1992), que em sua Parte II, artigo 2o, item 1 prevê que cada Estado Parte compromete-se a adotar medidas que visem a assegurar de forma progressiva o pleno exercício dos direitos reconhecidos no Pacto.
}

Revista do Direito [ISSN 1982-9957]. Santa Cruz do Sul, v. 3, n. 53, p. 2-22, set./dez. 2017. https://online.unisc.br/seer/index.php/direito/index 
procedimental deve garantir justiça no sentido da regulamentação imparcial de questões práticas (HABERMAS, 1996, p. 313).

$\mathrm{Na}$ concepção de Harbermas, não se trata mais do que é bom para nós como membros de uma coletividade (caracterizada por um ethos próprio), mas sim do que é "correto" para todos, seja para todos os membros do universo de sujeitos capazes de agir ou fazer uso da linguagem, seja para todos os integrantes de uma comunidade jurídica (pode ser esta local ou até mesmo global, conforme o caso). E, ao julgar essas questões de justiça, procura-se uma solução imparcial, em relação à qual todos os participantes (e atingidos) não tivessem saída senão manifestar sua concordância, depois de muito ponderar sobre ela, no contexto de um diálogo isento de coerções e "mantido sob condições simétricas de reconhecimento recíproco" (HABERMAS,1996, p. 313).

Além disso, o autor explica dois pontos relevantes em sua obra: "por que é necessária a premissa da resposta correta única? E como, em último caso, ela pode ser conciliada com a evidência do dissenso permanente, que prepondera?" O autor responde à primeira pergunta afirmando que é fazê-la a contrário. Se tomar o Estado constitucional por uma ordem legítima, que por sua vez torna possível haver uma legislação legítima (bem como processos de criação do direito legítimos em geral), e se se entende "legitimidade" em um sentido não-empirista", pode-se supor a possibilidade de um acordo mútuo não-violento quanto a questões políticas. O autor também afirma que o processo democrático só promete uma racionalidade procedimental "imperfeita", mas "pura" sob a premissa de que, em princípio, os participantes considerem possível haver justamente uma resposta correta também para as questões de justiça. Em tal medida subsiste uma analogia em relação à disputa sobre questões factuais, "a qual não levaríamos adiante com recursos argumentativos, caso não tomássemos como ponto de partida que, em princípio, podemos nos convencer da verdade ou falsidade de um enunciado" (HABERMAS, 1996, p. 315, 324-355).

E como observa Alessandra Genú Pacheco, a diferença entre a ética habermasiana e outras éticas de herança kantiana pode ser percebida quando se delimita o caráter formal da ética. Para Kant, o princípio formal a partir do qual se pode verificar a moralidade de qualquer ação é um imperativo categórico, mas para Habermas, esse princípio formal é o princípio da argumentação, "sendo universalmente moral e obrigatória toda norma que puder ser sustentada em um discurso prático moral argumentativo". E na realidade o discurso argumentativo sobre as normas não conduzirá necessariamente ao consenso de um auditório universal (consenso fático), pois, desde que se adote o "ponto de vista moral", o consenso será válido. Este permite uma avaliação imparcial das questões morais. "Nesse ponto de vista, pressupõe-se que todos os indivíduos entrem no discurso como agentes livres e iguais, em uma busca cooperante da verdade, na qual interessa apenas a força do melhor argumento". O valor deste procedimento está em servir de parâmetro de avaliação para os procedimentos discursivos de que se participa (PACHECO, 2010, p. 105).

No tópico "inclusão com sensibilidade para as diferenças" da obra "A inclusão do outro", o autor preceitua que a leitura liberalista da autodeterminação democrática mascara o problema das minorias "inatas", que é percebido com maior clareza a partir do ponto de vista comunitarista. 0 problema também surge em sociedades democráticas, quando uma cultura majoritária, no exercício do poder político, impinge às minorias a sua forma de vida, e, assim, nega aos cidadãos de origem

Revista do Direito [ISSN 1982-9957]. Santa Cruz do Sul, v. 3, n. 53, p. 2-22, set./dez. 2017. https://online.unisc.br/seer/index.php/direito/index 
cultural diversa, a efetiva igualdade de direitos. "Isso tange questões políticas, que tocam o autoentendimente ético e a identidade dos cidadãos". O princípio majoritário chega ao seu limite, porque a composição do conjunto dos cidadãos condiciona os resultados de um processo aparentemente neutro (HABERMAS, 1996, p. 170-173).

Assim, preceitua que o problema das "minorias inatas" explica-se pelo fato de que os cidadãos, mesmo quando observados como personalidades jurídicas, não são indivíduos abstratos, amputados de suas relações de origem. "Na medida em que o direito intervém em questões éticopolíticas, ele toca a integridade das formas de vida dentro das quais está enfronhada a configuração pessoal de cada vida". Com isso, entram em jogo, ao lado de considerações morais, de reflexões pragmáticas e de "interesses negociáveis", valorizações fortes, que dependem de "tradições intersubjetivamente compartidas", mas culturalmente específicas. As ordens de direito também são, em seu todo, "eticamente impregnadas", porque interpretam o conteúdo universalista dos mesmos princípios constituintes de modo diferente em cada caso, a saber, no contexto das experiências de uma historia nacional e á luz de uma tradição, uma cultura e uma forma de vidas historicamente predominantes (HABERMAS, 1996, p. 170-173).

E este problema das "minorias inatas", que pode surgir em todas as sociedades pluralistas, agudiza-se nas sociedades multiculturais. Contudo, quando estas estão organizadas como Estados democráticos de direito, apresentam-se, todavia, diversos caminhos para se chegar a uma inclusão "com sensibilidade para as diferenças": a divisão federalista dos poderes, uma delegação ou descentralização funcional e específica das competências do Estado, mas principalmente, a concessão de autonomia cultural, os direitos grupais específicos, as políticas de equiparação e outros arranjos que levem a uma efetiva proteção das minorias. Dessa forma, dentro de determinados territórios e em determinados campos políticos, mudam as totalidades fundamentais dos cidadãos que participam do processo democrático, sem tocar nos seus princípios (HABERMAS, 1996, p. 170173).

Desse modo, para Habermas, a coexistência da igualdade de direitos de diferentes comunidades étnicas, grupos linguísticos, confissões religiosas e formas de vida, não pode ser obtida ao preço da fragmentação da sociedade. Por um lado, a cultura majoritária deve se soltar de sua função com a cultura política geral, uniformemente compartida por todos os cidadãos; "caso contrário, ela ditará a priori os parâmetros dos discursos de auto-entendimento". Assim, "como parte, não mais poderá constituir-se em fachadas do todo, se não quiser prejudicar o processo democrático em determinadas questões existenciais, relevantes para as minorias" (HABERMAS, 1996, p. 170-173).

Por outro lado, as forças de coesão da cultura política comum - a qual se torna tanto mais abstrata quanto mais forem as subculturas para as quais ela é o denominador comum - devem continuar a ser suficientemente fortes para que a nação dos cidadãos não se despedace: "o multiculturalismo, ao mesmo tempo que apóia a perpetuação de vários grupos culturais dentro de uma mesma sociedade política, também requer a existência de uma cultura comum". Membros de todos os grupos terão de adquirir uma linguagem política e convenções de comportamento comuns para poder participar eficientemente na competição por recursos e na proteção dos interesses do grupo, assim como dos interesses individuais numa arena política compartida (HABERMAS, 1996, p. 
170-173). E esse todo não pode excluir os cidadãos mais vulneráveis pela sua situação econômica, como se pretende na atual conjuntura política brasileira.

Dessa forma, apoiando-se ainda em outras leituras acerca do pensamento do autor, verificase que nesta obra ("A inclusão do outro"), Habermas defende que pela ampliação da participação política, por meio da inclusão de novos cidadãos no contexto de uma maior integração social, deve surgir uma cultura democrática que sustente o processo democrático. Todavia, é necessário lutar contra a crescente marginalização da política por parte do mercado sem lançar mão de soluções simples (e falsas) de regimes populistas e de extrema direita. Dessa forma, tenta ver tendências positivas, potencialmente emancipatórias, também no fenômeno típico da globalização e se confronta criticamente com o modelo neoliberal que se funda em uma dupla simplificação: a) a liberdade é entendida unicamente como liberdade de sujeitos econômicos ou de concorrentes, e não como autonomia política de cidadãos republicanos; b) o processo democrático serve à defesa desta liberdade mutilada e não à autolegislação de sujeitos politicamente autônomos. E contra este modelo, no seu cenário de estudo, oferece um modelo de uma Europa integrada economicamente e em questões de direito civil, mas também política e economicamente (PINZANI, 2009, p. 157).

O autor desenvolve a temática da inclusão do outro considerando os distintos âmbitos e problemas do mundo contemporâneo e sugere impedir que a identidade coletiva se torne um mecanismo de "exclusão do diferente", sendo que tal exclusão provoca a marginalização interna de grupos sociais inteiros. Os meios de comunicação, a crescente diversidade cultural das sociedades contemporâneas e seus conflitos com a globalização, o esvaziamento da democracia e a tomada de consciência do caráter global dos direitos humanos são perspectivas que Habermas leva em consideração na sua análise e fazem com que sugira uma tentativa de impedir que a identidade coletiva se torne um mecanismo de exclusão do diferente. "Sendo que tal exclusão se dá por meio de uma vontade consciente de homogeneidade social e que provoca a marginalização interna de grupos sociais inteiros". E contra a exclusão sistemática Habermas defende que a política própria da democracia deve ser dirigida na direção da "inclusão do outro", promovendo a independência da procedência cultural de cada qual e as vias de acesso à comunidade política que devem permanecer sempre abertas (FREITAS, 2016).

Isto é, na obra aqui estudada, Habermas trata das consequências do conteúdo universalista dos princípios republicanos para as sociedades pluralistas nas quais os contrastes multiculturais são agudos, defendendo o conteúdo racional de uma moral baseada no mesmo respeito por todos e na responsabilidade solidária geral de cada um pelo outro. Ou seja, a política própria da democracia deve "incluir o outro", permanecendo a comunidade política aberta para o acesso de todos os grupos.

Mas não é o que ocorre no atual cenário político-econômico brasileiro, no qual se verifica que as pessoas que pertencem às classes de baixa renda são excluídas deste processo de diálogo e deliberação. Portanto, deve-se considerar a concepção habermasiana no sentido de inclusão do outro, reconhecendo-se a identidade dos grupos marginalizados pela sociedade, impondo-se a "sensação de pertencimento". O não reconhecimento de determinados grupos ou cidadãos implica numa sociedade incoerente, que não exprime a vontade de todos. 
Desse modo, tem-se que os programas sociais que garantem os direitos mais básicos para 0 cidadão, possibilitando a saída de tais grupos da miserabilidade, a exemplo do "Bolsa Família" e do "Minha Casa, Minha Vida", são essenciais para a inclusão de tais grupos na sociedade e nos respectivos processos de deliberação, e, por isso, não pode haver qualquer retrocesso em relação às garantias já conquistadas.

\section{CONSIDERAÇÕES FINAIS}

Consoante acima exposto, pode-se concluir que os direitos sociais previstos no rol do artigo 60 da Constituição da República de 1988, assim como a legislação e os serviços públicos em prol de sua efetivação, são direitos fundamentais, e, assim, possuem tratamento diferenciado, com a incidência, inclusive, do que a doutrina denomina de princípio da proibição de retrocesso social. Desse modo, o Legislativo e o Executivo não podem realizar cortes ou abolir programas sociais, mormente diante do que prevê a Constituição como objetivos da República em seu artigo 3o, sob pena de se violar o núcleo mínimo de direitos da pessoa e a própria dignidade da pessoa humana, e porque no Brasil ainda se tem altos níveis de exclusão social, fazendo-se necessária a defesa do Estado Social.

No caso brasileiro, os períodos de crise econômica tampouco podem suscitar eventuais medidas restritivas de direitos sociais, tendo em vista que, em paralelo às medidas de cortes em programas sociais, o governo anunciou o reajuste nos salários dos servidores federais, como também pela má gestão dos recursos públicos. A crise brasileira é "institucional", tendo em vista que as medidas anunciadas fecham um ciclo de políticas intervencionistas, anticíclicas e de pleno emprego, para inaugurar um Estado voltado para a austeridade e restrição orçamentária. E mesmo no contexto europeu, no qual as mazelas da corrupção e da má gestão de recursos são menos frequentes, também se verifica que, em períodos de crise, a recomendação da Corte Europeia foi a manutenção dos direitos sociais em relação às medidas de austeridade.

Isto é, os direitos sociais não podem ser violados sob a justificativa de que há crise econômica, enquanto apenas as camadas mais pobres da população suportam o prejuízo da crise, seja sob o ponto de vista da vedação ao retrocesso aqui defendida, seja sob o viés da restrição aos direitos fundamentais, tendo em vista a peculiaridade da gestão de recursos públicos no Brasil. Além disso, sob o aspecto da legitimidade, pode-se questionar o atual governo, tendo em vista que foi eleito como vice-presidente com um programa social totalmente diferenciado das medidas de cortes em programas sociais que tem anunciado.

Também se conclui que as medidas que restringem parcial ou totalmente os programas sociais para a efetivação dos direitos sociais mais básicos acabam por gerar a exclusão (no sentido proposto por Habermas), e, como se verificou, somente o Estado é forte o suficiente para efetivar tais direitos, sendo necessário, inclusive, que se construa um real espaço público político, para a deliberação de tais questões, a partir de uma igualdade gerada pelo Estado. 


\section{REFERÊNCIAS}

ABRASCO - Associação brasileira de saúde coletiva. Disponível em: https://www.abrasco.org.br/site/2016/05/gastao-wagner-excluir-o-direito-a-saude-e-barbarie/. Acesso em: 11.08.2016.

ALESSI, Gil. Entenda o que é a PEC 241 (ou 55) e como ela pode afetar sua vida. EI País. Disponível em: http://brasil.elpais.com/brasil/2016/10/10/politica/1476125574_221053.html. Acesso em: 03.01.2017.

AYALA, Patryck de Araújo. O princípio da proibição de retrocesso ambiental na jurisprudência do superior tribunal de justiça - o caso city lapa. In: Revista de Direito Ambiental, vol. 62/2011, p. 403 419, Abr - Jun, 2011.

ARAÚJO, Joelma Maria Batista de; FERREIRA JUNIOR, Reynaldo Rubem. O ciclo econômico da teoria schumpeteriana e as crises financeiras. In: Sociedade Brasileira de Economia Política SEP. Disponível em:

http://www.sep.org.br/artigos/download?id=1798\&title=O+Ciclo+Econ\%C3\%B4mico+da+Teoria+Schu mpeteriana+e+as+Crises+Financeiras. Acesso: 12.09.2016

BRASIL. Altera e revoga dispositivos da Lei no 10.683, de 28 de maio de 2003, que dispõe sobre a organização da Presidência da República e dos Ministérios. Disponível em:

http://www.planalto.gov.br/ccivil_03/_Ato2015-2018/2016/Mpv/mpv726.htm. Acesso em: 13.09.2016.

Supremo Tribunal Federal. ARE no 639337 AgR. Relator: Celso de Mello.Segunda Turma. Brasília, julgado 14 de setembro de 2011. Brasília, publicado15 set. 2011.

Decreto n. 591 de 6 julho de 1992. Atos Internacionais. Pacto Internacional sobre Direitos Econômicos, Sociais e Culturais. Diário Oficial da União. Brasília, 07.07.1992. Promulgação. Disponível em: http://www.planalto.gov.br/ccivil_03/decreto/1990-1994/d0591.htm. Acesso em: 15.09.2016.

BONAVIDES, Paulo. Curso de Direito Constitucional. São Paulo: Malheiros, 2007.

CANOTILHO, José Joaquim Gomes. Direito constitucional e Teoria da Constituição. Coimbra: Almedina, 2000.

CALEIRO, João Pedro. Mapa Coloca os Países com o Tamanho de Suas Dívidas. Exame. Disponível em: http://exame.abril.com.br/economia/noticias/mapa-coloca-os-paises-com-o-tamanho-de-suasdividas. Acesso em 12.09.2016.

CORTEZ, Ana Carolina. Reajuste do servidor e 14.000 novos cargos: austeridade de Temer em xeque. El País. Disponível em:

http://brasil.elpais.com/brasil/2016/06/04/economia/1464992955_507128.html. Acesso em: 03.09.2016.

CAPELLA, Juan Ramón. Fruta prohibida: una aproximación histórico-teorética al estudio del derechoy del estado. Madrid: Editorial Trotta, 2001.

CASTEL, Robert. As metamorfoses da questão social: uma crônica do salário. Petrópolis: Vozes, 2012.

DERBLI, Felipe. O Princípio da Proibição do Retrocesso Social na Constituição de 1988. Rio de Janeiro: Renovar, 2007.

O TEMPO. Silenciosamente Temer Prepara Reforma Trabalhista.Disponível em: http://www.otempo.com.br/capa/pol\%C3\%ADtica/silenciosamente-temer-j\%C3\%A1-prepara-reformatrabalhista-1.1304320. Acesso em: 31.08.2016. 
FREITAS, Carolina Nunes de; COURA, Alexandre de Castro. A teoria habermasiana de inclusão do outro e a internação compulsória. Disponível em:

http://www.publicadireito.com.br/artigos/?cod=7a71bed212ae4dc6. Acesso em: 11.09.2016.

GABARDO, Emerson. Interesse público e subsidiariedade: o Estado e a sociedade civil para além do bem e do mal. Belo Horizonte: Fórum, 2009.

HABERMAS, Jurgen. A inclusão do outro: estudos de teoria política. São Paulo: Loyola, 1996.

HACHEM, Daniel Wunder. Tutela administrativa efetiva dos direitos fundamentais sociais: por uma implementação espontânea, integral e igualitária. 2014. 614 fls. Tese (Doutorado em Direito), Universidade Federal do Paraná, Programa de Pós-graduação em Direito, Curitiba, 2014.

IFSC.Nota oficial: Corte de bolsas do CNPQ. Disponível em: http://www.ifsc.edu.br/institucional/6164nota-oficial-corte-de-bolsas-do-cnpq. Acesso em: 31.08.2016.

ORGANIZAÇÃO DOS ESTADOS AMERICANOS. Disponível em: $\mathrm{h}$ http://www.oas.org/pt/cidh/prensa/notas/2016/067.asp. Acesso em: 15.08.2016.

NOVAIS, Jorge Reis. Direitos sociais: teoria jurídica dos direitos sociais enquanto direitos fundamentais. Coimbra: Editora Coimbra, 2010.

PACHECO, Alessandra Genú. Ideologia e crítica na teoria da ação comunicativa. Discursos habermasianos. LIMA, Clóvis Ricardo Montenegro de; GÓMEZ, Maria Nélida Gonalez. Rio de Janeiro: IBICT, 2010.

PEDRAZA, Paula Garcia. Crisis and social rights in europe: retrogressive measures versus protection mechanisms. Institute for Human Rights Åbo Akademi University, 2014.

PINTO NETO, Moysés. O patrimonialismo anti-2013 no Poder. In: Medium, 2015. Disponível em: https://medium.com/@moysespintoneto/o-patrimonialismo-anti-2013-no-poder-

20b56b5cf004\#.gax9uj9ki. Acesso em: 14.08.2016.

NETTO, Luísa Cristina Pinto e. A abertura do sistema de direitos fundamentais do Estado Constitucional. Curitiba: Íthala, 2016.

O princípio de proibição de retrocesso social. Porto Alegre: Livraria do Advogado, 2010.

PINZANI, Alessandro. Habermas. Porto Alegre: Artmed, 2009.

REESE-SCHAFER, Walter. Compreender Habermas. Petrópolis: Vozes, 2012.

SARLET, Ingo Wolfgang. A Eficácia dos Direitos Fundamentais: uma teoria geral dos direitos fundamentais na perspectiva constitucional. Porto Alegre: Livraria do Advogado, 2010.

O estado social de direito, a proibição de retrocesso social e a garantia fundamental da propriedade. Revista eletrônica sobre a reforma do Estado. Salvador, n. 9, março, abril e maio, 2007.

SERRANO, Pedro Stevam. O governo Temer e a ameaça ao pacto social. Disponível em: http://www.cartacapital.com.br/sociedade/governo-temer-e-a-ameaca-ao-pacto-social. Acesso em: 15.08.2016.

SCHIER, Adriana da Costa Ricardo. Regime jurídico do Serviço Público: garantia fundamental do cidadão e proibição de retrocesso social. 2009. 224 fls. Tese (Doutorado) - Curso de Pós Graduação em Direito, Ciências Jurídicas, Universidade Federal do Paraná, Curitiba, 2009.

SCHUMPETER, Joseph Alois. Teoria do desenvolvimento econômico: uma investigação sobre lucros, capital, crédito, juro e o ciclo econômico. São Paulo: Nova cultural, 1988. 
Capitalismo, socialismo e democracia. Rio de Janeiro: Fundo de Cultura, 1961.

SZMRECSÁNYI, Tamás J. M. K. A Herança Schumpeteriana. In: Pelaez, Victor; Szmrecsányi, Tamás J. M. K. (Orgs.). Economia da Inovação Tecnológica. São Paulo: Hucitec e Ordem dos Economistas do Brasil, 2006.

VALOR ECONÔMICO. Governo acabará com subsídios à baixa renda no Minha Casa Minha Vida. Disponível em: http://www.valor.com.br/politica/4579501/governo-acabara-com-subsidios-baixarenda-no-minha-casa-diz-jornal. Acesso em: 03.09.2016.

WALLIN, Claudia. Temer coloca o Brasil na contramão das sociedades avançadas. 2016. Disponível em: http://www.diariodocentrodomundo.com.br/temer-coloca-o-brasil-na-contramao-das-sociedadesavancadas-por-claudia-wallin-da-suecia/. Acesso em: 15.08.2016.

WOLKMER, Antônio Carlos. Constitucionalismo e Direitos Sociais no Brasil. São Paulo: Acadêmica, 1989.

\section{COMO CITAR ESSE DOCUMENTO:}

DOTTA, Alexandre Godoy; MARQUES, Camila Salgueiro da Purificação. Programas sociais, a exclusão social e a vedação ao retrocesso: direitos sociais no Brasil em crise. Revista do Direito, Santa Cruz do Sul, v. 3, n. 53, dez. 2017. ISSN 1982-9957. Disponível em: $<$ https://online.unisc.br/seer/index.php/direito/article/view/9624>. Acesso em: doi:http://dx.doi.org/10.17058/rdunisc.v3i53.9624. 